\title{
4-Node Test Feeder with Step Voltage Regulators is
}

\author{
Cristina González-Morán*, Pablo Arboleya, Rejwan R. Mojumdar, Bassam Mohamed \\ Department of Electrical Engineering, University of Oviedo, Spain
}

\section{A R T I C L E I N F O}

\section{Article history:}

Received 26 January 2017

Received in revised form 14 June 2017

Accepted 23 June 2017

Available online 27 July 2017

\section{Keywords:}

Distribution System Analysis

Forward-backward sweep

Power transformers

Step Voltage Regulators

Unbalanced operation

\begin{abstract}
A B S T R A C T
This work has two main contributions; First, the development of a general, exact and standardized Step Voltage Regulator model considering all possible configurations and second, the proposal of a 4-Node Test System for testing and evaluation of three-phase Step Voltage Regulator connections. Although the 4-Node Test Feeder for testing three phase transformer configurations is already available in the literature, there is not such model for the inclusion, testing and validation of Step Voltage Regulators in a test feeder. With the work presented in this paper, a new test system will be available to evaluate and benchmark programs or algorithms that attempt to include different configurations of Step Voltage Regulators. The formulation is stated for all three phase Step Voltage Regulators; i.e. wye, close-delta and open-delta connections, both type A and B regulators, in raise or lower positions. Then, all these models are included in a 4-Node Test Feeder to obtain several power flow solutions. All obtained results will be available for power flow software developers on-line.
\end{abstract}

(c) 2017 Elsevier Ltd. All rights reserved.

\section{Introduction}

Step Voltage Regulators (SVRs) have been employed in power feeders for many decades [1-4]. Its modeling posses particular importance in power flow studies of unbalanced distribution networks [5-7] and is gaining even more importance in distribution feeders with the proliferation of Distributed Generation (DG) [8]; several voltage control possibilities can be achieved by coordinating the small generators and storage units installed near customers and the well-known switched capacitors and step voltage regulators [9]. As an example, the authors in [10] proposed a coordinated control of energy storage systems with SVRs to mitigate the voltage rise caused for high penetration levels of photovoltaic systems. Similar applications can be found in [11] or [12]; In both works the combination of SVRs, Static VAR Compensators (SVC) and Shunt Capacitors (SC) are applied to achieve voltage control in distribution feeders including DG. In [13] the control schedules of SVRs are updated according to wind power predictions to compensate voltage variations derived form high penetration of wind power plants. Many other works related to coordination of SVRs in distributed systems with DG can be

this work has been supported by the Research, Technological Development and Innovation Program Oriented to the Society Challenges of the Spanish Ministry or Economy and Competitiveness under Grant ENE 2013-44245-R.

* Corresponding author.

E-mail address: gonzalezmorcristina@uniovi.es (C. González-Morán).

URLs: http://cristina.dieecs.com/contact (C. González-Morán), http://arboleya. dieecs.com (P. Arboleya). found in the literature [14-17]. In [14] a voltage estimation is used to control over-voltages in residential networks with varying PV penetrations. In [15] the authors coordinate the location of reactive power injections from the PV inverters with transformer tap positions in a distributed system as a way to constrain voltage variations. In [16] an unbalanced power flow is used to obtain the influence of SVRs and DGs penetrations in power losses and voltage profiles. In [17] several voltage control techniques; On Load Tap Changers (OLTC), SVR, SC, Shunt Reactor (ShR), and SVC are optimally controlled in coordination with DG.

In [18] a robust, low-cost and high-efficiency voltage regulator is designed for rural networks with serial voltage compensation. In [19] the authors propose distributed voltage control for multiple voltage regulation devices; on-load tap changers, step voltage regulators and switched capacitors in the presence of PV. They tested the scheme in a medium voltage feeder in California. In [20] detailed models for open-delta connected SVR are presented. The authors developed a bus admittance model suitable for unbalanced power flow studies.

Regarding the optimization of tap positions, in [21] an algorithm to set the positions of regulating transformers is proposed. The algorithm is valid for unbalanced and distributed systems. In [22], the authors propose a linear power flow formulation to optimally configure a distribution system using, among other control variables, the tap positions in voltage regulators. In [23], also the tap positions of transformers are included as optimization variables. 
Directly related to SVR modeling, we can find the work in [24], in which there is a brief description of a SVR model to be included in an unbalanced power flow formulation based on the current injection method. In [25] the authors are capable of designing dynamic SVRs, but they considered a single phase model. From their point of view, this model can be used into a 3 phase system taking into account that each phase works separately, so they do not considered closed delta or open delta configurations. In $[26,27]$ Kersting addressed the modeling of some SVR configurations to study some of their applications. Those works cover the distribution system modeling in $a b c$ reference frame, the SVR control mechanism by estimating $R$ and $X$ line settings and other applications of SVRs in distribution systems.

Looking at this literature review we can conclude that SVR modeling and testing are of great importance for distribution systems and power flow studies, and are expected to be even more present with the proliferation of DG. However, we have found that, although there are many extensive works dealing with SVR inclusion in power flow studies, there is not any work presenting general models and results for all possible configurations. This work might be also used as a benchmark for other researchers.

Reviewing the IEEE test feeders [28] of the IEEE PES Distribution System Analysis Subcommittee's Distribution Test Feeder Working Group, we will find a set of common data for testing and validation of Distribution System Analysis software. More specifically, the 4-Node Test Feeder offers a set of comparison results to deal with transformers of various configurations [29].

In this paper, the IEEE 4-Node Test System in [28] will be modified; The transformer is removed to introduce SVRs instead. We propose the general model for SVR and the 4-Node Test Feeder with SVR, both of them will be available for designers and power flow developers as a test system with detailed SVR modeling and results.

The paper is structured as follows: First, a general matrix formulation will be stated for all possible configurations: 2 grounded-wye connections (type A and B regulators), 2 closedelta connections (type $A$ and $B$ ) and 6 open-delta connections depending on the selection of phases ( 3 cases for type A and 3 other cases for type B). The regulators can be at raise or at lower positions. All these SVR configurations defined a 4-Node Test Feeder that has been formulated in $\alpha \beta 0$ frame, following the procedure of [30], but adapted for SVRs. Then, the power flow formulation is presented for balanced and unbalanced loading at different tap positions. Finally, the problem is solved with the Backward Forward Sweep (BFS) algorithm of [31] to obtain the results for all possible configurations. Due to the high extension of results that were obtained, only some examples are included in this paper. The rest of results will be available on line (see Supplementary material).

\section{SVR modeling}

\subsection{Single phase Step Voltage Regulator}

A model for an ideal single phase regulator can be derived from [27]. If the series impedance is to be also considered, then, that ideal model needs to be modified: In Fig. 1 the single phase configurations are displayed. $P$ stands for primary (or source side) and $S$ stands for secondary (load side). For the sake of simplicity, as it will be justified later, the series impedance is concentrated at the secondary side for type A configurations and at the primary side for type B configurations. The relationships between voltages and currents for the ideal SVR are summarized in Table 1 , where $N_{1}$ and $\mathrm{N}_{2}$ are the number of turns of the shunt and series windings respectively. $a_{R}$ is the effective turns ratio and is defined in a different way depending on the type of regulator, as it is shown in the table. From Fig. 1 it can be deducted that $\mathrm{P}=\mathrm{P}^{\prime}$ for type $\mathrm{A}$ and $\mathrm{S}=\mathrm{S}^{\prime}$ for type $\mathrm{B}$ regulators.

The relationship between primary and secondary voltages for type $\mathrm{A}$, single phase regulators can then be written as follows:

$V_{P^{\prime}}=V_{S^{\prime}} \frac{1}{a_{R}}$

$V_{P^{\prime}}=V_{P}$

$V_{S^{\prime}}=V_{S}+Z I_{S}$

replacing (2) and (3) into (1) and taking $V_{P}$ apart, it is obtained:

$V_{P}=\frac{1}{a_{R}} V_{S}+\frac{1}{a_{R}} Z I_{S}$

For type A regulators, the primary and secondary currents can be related by:

$I_{P}=a_{R} I_{S}$

The corresponding equations for type $\mathrm{B}$, single phase regulators, with impedance on the primary side are stated as:

$V_{P^{\prime}}=V_{S^{\prime}} a_{R}$

$V_{S^{\prime}}=V_{S}$

$V_{P}=Z I_{P}+V_{P^{\prime}}$

replacing (6) and (7) into (8) it is deducted that:

$V_{P}=a_{R} V_{S}+Z I_{P}$

And finally, primary and secondary currents for type B regulators can be related in:

$I_{P}=\frac{1}{a_{R}} I_{S}$

Single phase Eqs. (4), (5) for type A regulators and (9), (10) for type $B$ regulators are the baseline for the definition of the three phase configurations.

\subsection{Three phase connections}

Three phase configurations to be considered are wye, close delta and open delta. In following subsections, upper cases letters will be used for primary (or source) side and lower case letters will represent secondary (or load) side. In the present work, type A regulators have been chosen for three phase connections. However, the same procedure can be extended to type B regulators. For the power flow calculations, the mathematical model in [30] and a BFS algorithm are going to be used. The formulation is valid for any transformer connection, and the algorithm in $\alpha \beta 0$ frame solves the problems of some transformer connections including three wire configurations ( $\Delta$ and ungrounded wye) in $a b c$ frame; especially $Y_{g} \Delta$ connection. The problems are solved by means of the zero components of voltages and currents that in $\alpha \beta 0$ frame are always available [30].

There are three general equations that represent all three phase connections:

$$
\begin{aligned}
& {[\mathbf{V}]_{\alpha \beta 0}^{\mathrm{P}}=\mathbf{N}_{\mathbf{I I}_{\alpha \beta 0}}[\mathbf{V}]_{\alpha \beta 0}^{\mathrm{S}}+Z \mathbf{N}_{\mathbf{I}_{\alpha \beta 0}}[\mathbf{I}]_{\alpha \beta 0}^{\mathrm{PS}}} \\
& {[0]=-[\mathbf{I}]_{\alpha \beta 0}^{\mathrm{P}}+\mathbf{N}_{\mathbf{I} \mathbf{V}_{\alpha \beta 0}}[\mathbf{I}]_{\alpha \beta 0}^{\mathrm{PS}}} \\
& {[0]=[\mathbf{I}]_{\alpha \beta 0}^{\mathrm{S}}+\mathbf{N}_{\mathbf{I I I}}[\mathbf{I}]_{\alpha \beta 0}^{\mathrm{PS}}}
\end{aligned}
$$

The sub-index $\alpha \beta 0$ are used in the expressions because all the elements in brackets are three phase $\alpha \beta 0$ components (voltages or currents). The super-indexes $\mathrm{P}$ and $\mathrm{S}$ stand for primary and secondary respectively. The super-index PS stands for primary or secondary, depending on the transformer connection. Eqs. (11)-(13) 


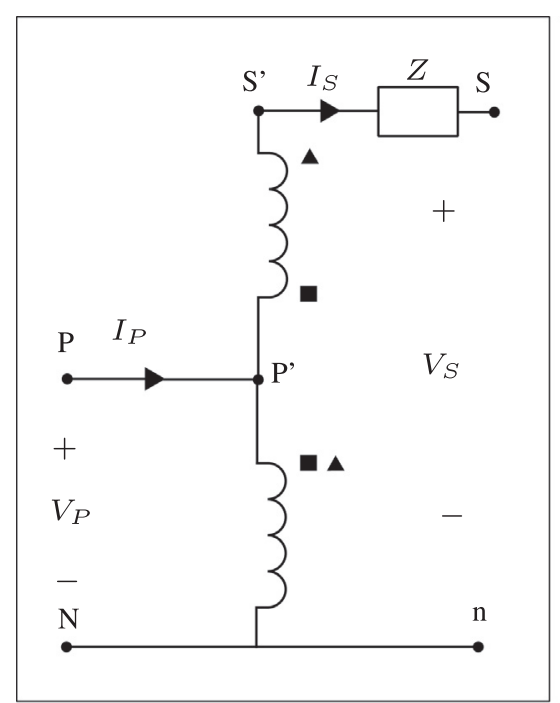

(a) Single Phase Type A

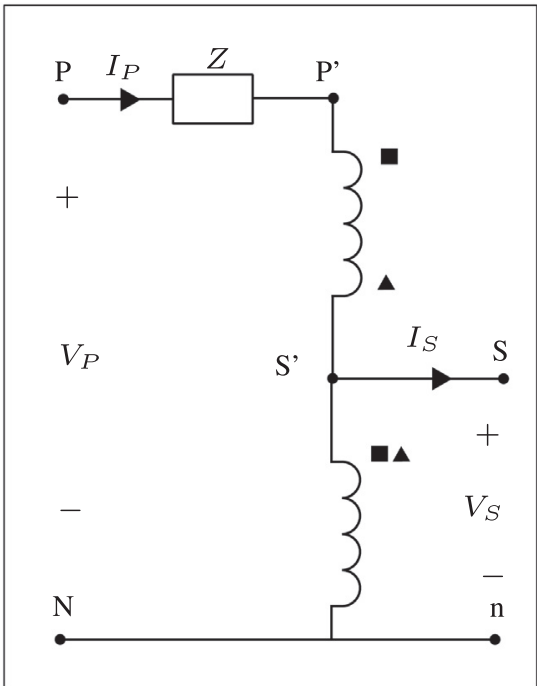

(b) Single Phase Type B

Fig. 1. SVR: Single Phase connections. $\Delta$ Raise position. $\mathbf{a}$ Lower position.

Table 1

Equations for ideal single phase SVRs.

\begin{tabular}{|c|c|c|c|c|c|}
\hline \multirow[t]{2}{*}{ Type } & \multicolumn{2}{|c|}{ Operator $\oplus$} & \multirow[t]{2}{*}{$a_{R}$} & \multirow{2}{*}{$\frac{V_{p^{\prime}}}{V_{S^{\prime}}}$} & \multirow[t]{2}{*}{$\frac{I_{P}}{I_{S}}$} \\
\hline & Lower & Raise & & & \\
\hline A & - & + & $1 \oplus \frac{N_{2}}{N_{1}}$ & $\frac{1}{a_{R}}$ & $a_{R}$ \\
\hline B & + & - & & $a_{R}$ & $\frac{1}{a_{R}}$ \\
\hline
\end{tabular}

comprise an exact model for three phase transformers, so they can be directly included in the power flow solver. The matrices $\mathbf{N}_{\mathrm{I}_{\alpha \beta 0}}, \mathbf{N}_{\mathrm{II}_{\alpha \beta 0}}, \mathbf{N}_{\mathrm{III}_{\alpha \beta 0}}$ and $\mathbf{N}_{\mathrm{IV}_{\alpha \beta 0}}$ are different for each transformer connection. Any transformer connection is defined by these four matrices and the phase impedance $Z$. These equations can be also used to model SVRs as it will be demonstrated.

The meaning of superscript PS will change with the type of regulator. If (11) is compared to (4) and (9), it seems as in the SVR case, it will be easy to consider that PS stands for secondary in type $A$ regulators and for primary in type $B$ regulators. This fact will be proven for each transformer connection. $Z$ is the transformer impedance, that is suppose to be the same for all the phases.

In the present work, the matrices $\mathbf{N}_{\mathrm{I}_{\alpha \beta 0}}, \mathbf{N}_{\mathrm{II}_{\alpha \beta 0}}, \mathbf{N}_{\mathrm{III} \alpha \beta 0}$ and $\mathbf{N}_{\mathrm{IV}} \mathrm{I}_{\alpha \beta 0}$ will be defined to include any type of SVR configuration in the power flow solution. The equations are firstly described in $a b c$ frame, so those matrices are obtained in $a b c$ frame and transformed into $\alpha \beta 0$ frame using the transformation matrix $\mathbf{A}$ in (14).

$$
\mathbf{A}=\sqrt{\frac{2}{3}}\left(\begin{array}{rrr}
1 & 0 & \frac{1}{\sqrt{2}} \\
-\frac{1}{2} & \frac{\sqrt{3}}{2} & \frac{1}{\sqrt{2}} \\
-\frac{1}{2} & -\frac{\sqrt{3}}{2} & \frac{1}{\sqrt{2}}
\end{array}\right)
$$

\subsubsection{Wye-connected regulators}

Three phase wye-connected regulators are depicted in Fig. 2a (type A) and Fig. 2b (type B). The winding polarities are shown for both raise and lower positions. The equations that relate primary and secondary phase to neutral voltages are similar to those for the single phase (4), but extended to the three phase wye connection:

$$
\begin{aligned}
& {\left[\begin{array}{l}
V_{A} \\
V_{B} \\
V_{C}
\end{array}\right]=\left(\begin{array}{ccc}
\frac{1}{a_{R_{a}}} & 0 & 0 \\
0 & \frac{1}{a_{R_{b}}} & 0 \\
0 & 0 & \frac{1}{a_{R_{c}}}
\end{array}\right)\left[\begin{array}{l}
V_{a} \\
V_{b} \\
V_{c}
\end{array}\right]+\cdots} \\
& +\cdots Z\left(\begin{array}{ccc}
\frac{1}{a_{R_{a}}} & 0 & 0 \\
0 & \frac{1}{a_{R_{b}}} & 0 \\
0 & 0 & \frac{1}{a_{R_{c}}}
\end{array}\right)\left[\begin{array}{l}
I_{a} \\
I_{b} \\
I_{c}
\end{array}\right]
\end{aligned}
$$

This equation can be expressed in matrix form:

$[\mathbf{V}]_{a b c}^{\mathrm{P}}=\mathbf{N}_{\mathrm{II}_{a b c}}[\mathbf{V}]_{a b c}^{\mathrm{S}}+Z \mathbf{N}_{\mathrm{I}_{a b c}}[\mathbf{I}]_{a b c}^{\mathrm{S}}$

where

$\mathbf{N}_{\mathrm{I}_{a b c}}=\mathbf{N}_{\mathrm{II}_{a b c}}=\left(\begin{array}{ccc}\frac{1}{a_{R_{a}}} & 0 & 0 \\ 0 & \frac{1}{a_{R_{b}}} & 0 \\ 0 & 0 & \frac{1}{a_{R_{c}}}\end{array}\right)$

Translating Eq. (16) into $\alpha \beta 0$ frame, the resulting equation is:

$\mathbf{A}[\mathbf{V}]_{\alpha \beta 0}^{\mathrm{P}}=\mathbf{N}_{\mathrm{II}_{a b c}} \mathbf{A}[\mathbf{V}]_{\alpha \beta 0}^{\mathrm{S}}+Z \mathbf{N}_{\mathrm{I}_{a b c}} \mathbf{A}[\mathbf{I}]_{\alpha \beta 0}^{\mathrm{S}}$

and taking $[\mathbf{V}]_{\alpha \beta 0}^{\mathrm{P}}$ apart, the following equation applies:

$[\mathbf{V}]_{\alpha \beta 0}^{\mathrm{P}}=\mathbf{N}_{\mathbf{I I}_{\alpha \beta 0}}[\mathbf{V}]_{\alpha \beta 0}^{\mathrm{S}}+Z \mathbf{N}_{\mathbf{I}_{\alpha \beta 0}}[\mathbf{I}]_{\alpha \beta 0}^{\mathrm{S}}$

where two of the four generalized matrices are defined:

$\mathbf{N}_{\mathrm{I}_{\alpha \beta 0}}=\mathbf{A}^{-1} \mathbf{N}_{\mathrm{I}_{a b c}} \mathbf{A}$

$\mathbf{N}_{\mathrm{II}_{\alpha \beta 0}}=\mathbf{A}^{-1} \mathbf{N}_{\mathrm{II}_{a b c}} \mathbf{A}$ 


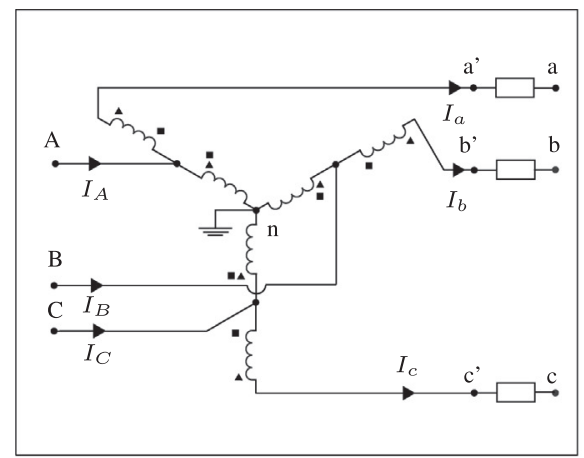

(a) Wye Type A

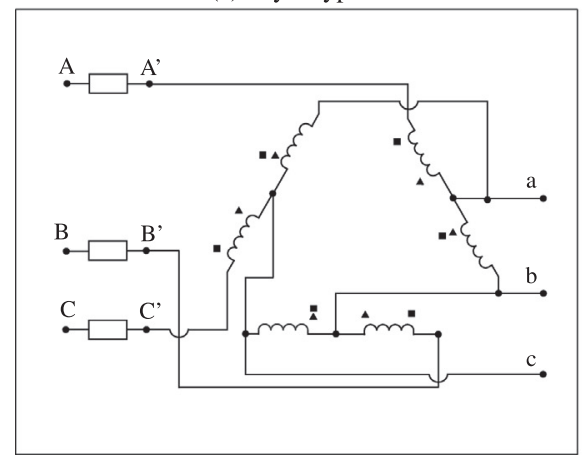

(d) Close Delta Type B

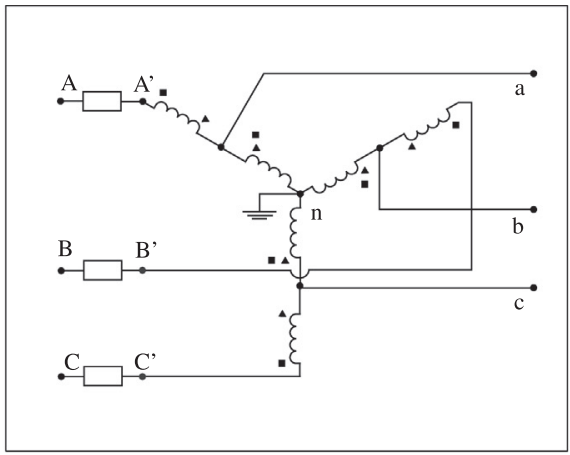

(b) Wye Type B

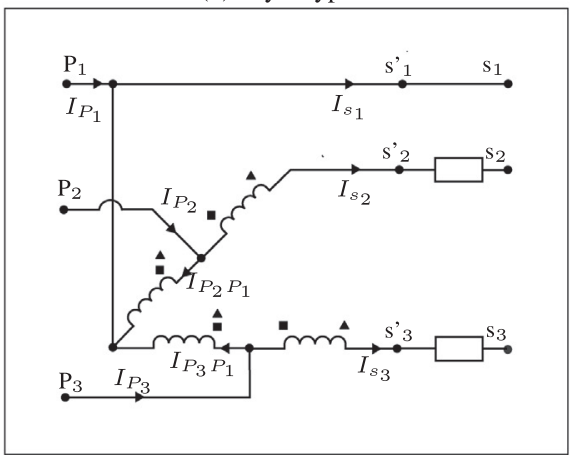

(e) Open Delta Type A

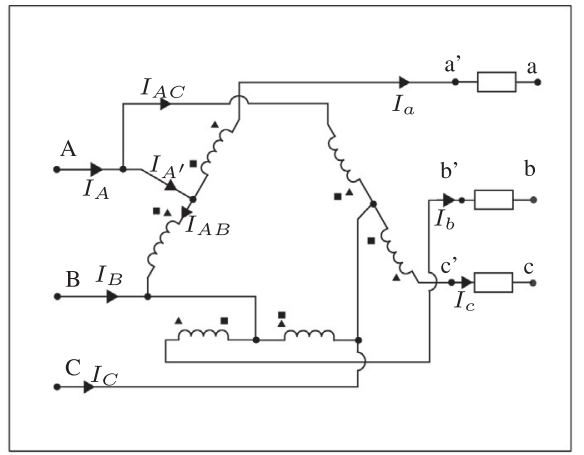

(c) Close Delta Type A

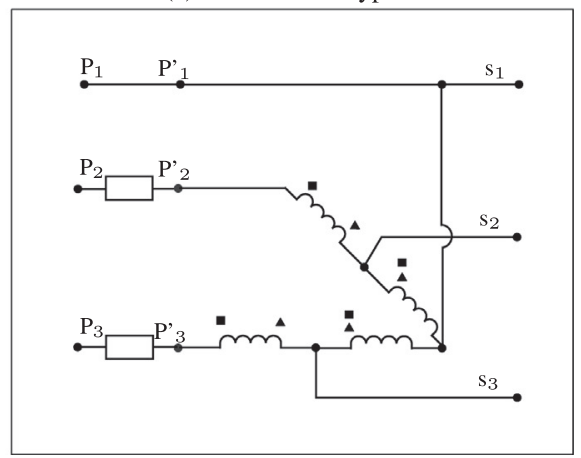

(f) Open Delta Type B

Fig. 2. SVR: Three Phase connections. $\Delta$ Raise position. $\mathbf{a}$ Lower position.

Eq. (19) is already of the same form as (11), proving that $[\mathbf{I}]_{\alpha \beta 0}^{\mathrm{PS}}$ are secondary currents for wye type A configurations. For the case of type $B$ regulators primary currents would be needed instead.

To derive the relationships between primary and secondary currents, from (5) the resulting three phase equation is:

$\left[\begin{array}{l}I_{A} \\ I_{B} \\ I_{C}\end{array}\right]=\left(\begin{array}{ccc}a_{R_{a}} & 0 & 0 \\ 0 & a_{R_{b}} & 0 \\ 0 & 0 & a_{R_{c}}\end{array}\right)\left[\begin{array}{l}I_{a} \\ I_{b} \\ I_{c}\end{array}\right]$

Rewriting this equation in matrix form:

$[\mathbf{I}]_{a b c}^{\mathrm{P}}=\mathbf{N}_{\mathrm{IV}_{a b c}}[\mathbf{I}]_{a b c}^{\mathrm{S}}$

where

$\mathbf{N}_{\mathrm{IV}_{a b c}}=\left(\begin{array}{ccc}a_{R_{a}} & 0 & 0 \\ 0 & a_{R_{b}} & 0 \\ 0 & 0 & a_{R_{c}}\end{array}\right)$

Translating this equation into $\alpha \beta 0$ frame and taking all terms to the right, Eq. (25) applies:

$[0]=-[\mathbf{I}]_{\alpha \beta 0}^{\mathrm{P}}+\mathbf{N}_{\mathrm{IV}_{\alpha \beta 0}}[\mathbf{I}]_{\alpha \beta 0}^{\mathrm{S}}$

Eq. (25) can be now identified with (12), being $[\mathbf{I}]_{\alpha \beta 0}^{\mathrm{PS}}$ equal to $[\mathbf{I}]_{\alpha \beta 0}^{\mathrm{S}}$ in this case. From (25) another generalized matrix in $\alpha \beta 0$ frame can be derived as:

$\mathbf{N}_{\mathrm{IV} \alpha \beta 0}=\mathbf{A}^{-1} \mathbf{N}_{\mathrm{IV}_{a b c}} \mathbf{A}$

To obtain the last generalized matrix $\mathbf{N}_{\mathrm{III} \alpha \beta 0}$, an equation similar to (13) has to be written. First, it can be assured that Eq. (27) applies:

$[0]=[\mathbf{I}]_{a b c}^{\mathrm{S}}-[\mathbf{I}]_{a b c}^{\mathrm{S}}$

Then, introducing matrix $\mathbf{N}_{\mathrm{III}}$ ibc in (28)
$\mathbf{N}_{\mathrm{III}_{a b c}}=-\left(\begin{array}{ccc}1 & 0 & 0 \\ 0 & 1 & 0 \\ 0 & 0 & 1\end{array}\right)$

Eq. (27) becomes:

$[0]=[\mathbf{I}]_{a b c}^{\mathrm{S}}+\mathbf{N}_{\mathrm{III}_{a b c}}[\mathbf{I}]_{a b c}^{\mathrm{S}}$

Translating into $\alpha \beta 0$ frame the resulting expression is:

$[0]=[\mathbf{I}]_{\alpha \beta 0}^{\mathrm{S}}+\mathbf{N}_{\mathrm{III}_{\alpha \beta 0}}[\mathbf{I}]_{\alpha \beta 0}^{\mathrm{S}}$

where

$\mathbf{N}_{\mathrm{III} \alpha \beta 0}=\mathbf{A}^{-1} \mathbf{N}_{\mathrm{III}_{a b c}} \mathbf{A}$

Considering in this case that $[\mathbf{I}]_{\alpha \beta 0}^{\mathrm{PS}}$ are secondary currents, (30) is of the same form as (13), so the model is feasible to be introduced into the power flow formulation of [30].

The four Eqs. (20), (21), (26) and (31) demonstrate that for a generic matrix in $a b c$ frame, $\mathbf{N}_{a b c}$, the corresponding matrix in $\alpha \beta 0$ frame, $\mathbf{N}_{\alpha \beta 0}$, can be computed as:

$\mathbf{N}_{\alpha \beta 0}=\mathbf{A}^{-1} \mathbf{N}_{a b c} \mathbf{A}$

The four matrices $\mathbf{N}_{\mathrm{I}_{a b c}}, \mathbf{N}_{\mathrm{II}}, \mathbf{N}_{\mathrm{II} a b c}$ and $\mathbf{N}_{\mathrm{IV}}$ abc are presented in Table 4 for this connection and also for subsequent connections. $I_{d(3 \times 3)}$ stands for the identity matrix with dimensions $(3 \times 3)$. Because all matrices are defined in terms of effective turns ratio instead of number of turns, they are valid for both raise and lower positions.

\subsubsection{Close delta-connected regulators}

Three single phase regulators can be connected in close-delta configurations as shown in Fig. 2c (type A) and 2d (type B). Both lower and raise positions give different polarities in the windings, as it is also depicted. For close-delta connections line to line voltages have to be considered. The relationship between primary 
and secondary phase-to-phase voltages in type A close-delta case, is given by (refer to $2 \mathrm{c}$ ):

$V_{A B}+V_{B b^{\prime}}+V_{b^{\prime} a^{\prime}}+V_{a^{\prime} A}=0$

So secondary voltage $V_{a^{\prime} b^{\prime}}$ can be written as:

$V_{a^{\prime} b^{\prime}}=V_{A B}+V_{B b^{\prime}}+V_{a^{\prime} A}$

The voltages $V_{A B}$ and $V_{a^{\prime} A}$ are related by the effective turns ratio for the regulator connected between phases $A$ and $B$ [27]. The same assumption can be made for voltages $V_{B C}$ and $V_{b^{\prime} B}$. If the shunt winding has a number of turns $N_{1}$, the series winding has a number of turns $\mathrm{N}_{2}$ and the raise position is taken in consideration then:

$\frac{V_{A B}}{V_{a^{\prime} A}}=\frac{N_{1}}{N_{2}}$

$\frac{V_{B C}}{V_{b^{\prime} B}}=\frac{N_{1}}{N_{2}}$

If $V_{B b^{\prime}}$ and $V_{a^{\prime} A}$ are replaced into (34) by their relations to $V_{A B}$ and $V_{B C}$ using (35) and (36) it is deducted that:

$V_{a^{\prime} b^{\prime}}=V_{A B}\left(1+\frac{\mathrm{N}_{2}}{\mathrm{~N}_{1}}\right)+V_{B C}\left(-\frac{\mathrm{N}_{2}}{\mathrm{~N}_{1}}\right)$

If the positions of the reversing switches of all regulators are in raise, this equation can be rewritten in terms of the effective turns ratios (see Table 1); i.e. $a_{R_{a b}}$ (for the regulator between phases $A$ and $B$ ) and $a_{R_{b c}}$ (for the regulator between phases $B$ and $C$ ):

$V_{a^{\prime} b^{\prime}}=a_{R_{a b}} V_{A B}+\left(1-a_{R_{b c}}\right) V_{B C}$

If the same procedure is followed for obtaining the voltages $V_{b^{\prime} c^{\prime}}$ and $V_{c^{\prime} a^{\prime}}$, the resulting three phase equation is:

$$
\left[\begin{array}{c}
V_{a^{\prime} b^{\prime}} \\
V_{b^{\prime} c^{\prime}} \\
V_{c^{\prime} a^{\prime}}
\end{array}\right]=\left(\begin{array}{ccc}
a_{R_{a b}} & 1-a_{R_{b c}} & 0 \\
0 & a_{R_{b c}} & 1-a_{R_{c a}} \\
1-a_{R_{a b}} & 0 & a_{R_{c a}}
\end{array}\right)\left[\begin{array}{c}
V_{A B} \\
V_{B C} \\
V_{C A}
\end{array}\right]
$$

With a similar reasoning for lower positions in the regulators, the same expression would be derived, so regardless of whether the regulators are raising or lowering the voltages, the same Eq. (39) applies. If the matrix of Eq. (39) is renamed as $\mathbf{A}_{R_{V}}$ (it is a non-singular matrix and has inverse) the primary voltages are obtained as:

$[\mathbf{V}]_{a b c}^{S^{\prime}}=\mathbf{A}_{R_{V}}[\mathbf{V}]_{a b c}^{\mathrm{P}}$

As it was explained in the previous subsection, being the regulators of type $A$, the impedances must be considered into the secondary side. Then, the matrix equation that includes the drop across those impedances is given by:

$$
\left[\begin{array}{c}
V_{a^{\prime} a} \\
V_{b^{\prime} b} \\
V_{c^{\prime} c}
\end{array}\right]=Z\left[\begin{array}{c}
I_{a} \\
I_{b} \\
I_{c}
\end{array}\right]
$$

The phase to phase voltages in the secondary side are then computed as:

$$
\left[\begin{array}{l}
V_{a^{\prime} b^{\prime}} \\
V_{b^{\prime} c^{\prime}} \\
V_{c^{\prime} a^{\prime}}
\end{array}\right]=\left[\begin{array}{l}
V_{a b} \\
V_{b c} \\
V_{c a}
\end{array}\right]+\left(\begin{array}{ccc}
1 & -1 & 0 \\
0 & 1 & -1 \\
-1 & 0 & 1
\end{array}\right)\left[\begin{array}{l}
V_{a^{\prime} a} \\
V_{b^{\prime} b} \\
V_{c^{\prime} c}
\end{array}\right]
$$

The matrices of Eq. (42) will be labeled as $\mathbf{T}_{\mathrm{DY}}$. It is a singular matrix. Substituting Eq. (41) into (42) and writing it into matrix form:

$[\mathbf{V}]_{a b c}^{S^{\prime}}=[\mathbf{V}]_{a b c}^{S}+Z \mathbf{T}_{D Y}\left[\mathbf{I}_{a b c}^{S}\right.$

Merging Eqs. (40) and (43) and taking primary voltages apart, the resulting equation is:
$\left[\mathbf{V}_{a b c}^{\mathrm{P}}=\mathbf{A}_{R_{V}}^{-1}[\mathbf{V}]_{a b c}^{\mathrm{S}}+\mathbf{A}_{R_{V}}^{-1} Z \mathbf{T}_{\mathrm{DY}}[\mathbf{I}]_{a b c}^{\mathrm{S}}\right.$

Eq. (44) might be written in the same form of (11). A comparison between both equations reveals:

$\mathbf{N}_{\mathbf{I}_{a b c}}=\mathbf{A}_{R_{V}}^{-1} \mathbf{T}_{\mathrm{DY}}$

$\mathbf{N}_{\mathbf{I I}_{\mathrm{abc}}}=\mathbf{A}_{R_{V}}^{-1}$

To derive the relationships between primary and secondary currents, if current references are taken as they are shown in Fig. 2c, it can be assured that:

$I_{A}=I_{A^{\prime}}+I_{A C}$

$I_{A^{\prime}}=I_{a}+I_{A B}$

Again, the relationship between currents through shunt and series windings can be computed in terms of the turns ratio:

$\frac{I_{A C}}{I_{C}}=-\frac{N_{2}}{N_{1}}$

$\frac{I_{A B}}{I_{a}}=\frac{N_{2}}{N_{1}}$

Merging Eqs. (47)-(50) into one equation it can be said that:

$I_{A}=I_{a}\left(1+\frac{N_{2}}{N_{1}}\right)+I_{c}\left(-\frac{N_{2}}{N_{1}}\right)$

Because the regulators are in raise position, Eq. (51) can be written as (see Table 1):

$I_{A}=a_{R_{a b}} I_{a}+\left(1-a_{R_{c a}}\right) I_{c}$

In a similar manner, the primary currents $I_{B}$ and $I_{C}$ can be also expressed in terms of secondary currents and effective turns ratios. The generalized matrix equation that relates primary and secondary currents is finally given by:

$\left[\begin{array}{c}I_{A} \\ I_{B} \\ I_{C}\end{array}\right]=\left(\begin{array}{ccc}a_{R_{a b}} & 0 & 1-a_{R_{c a}} \\ 1-a_{R_{a b}} & a_{R_{b c}} & 0 \\ 0 & 1-a_{R_{b c}} & 0\end{array}\right)\left[\begin{array}{c}I_{a} \\ I_{b} \\ I_{c}\end{array}\right]$

Labeling the matrix of (53) as $A_{R_{l}}$, the Eq. (53) becomes:

$\left[\mathbf{I}_{a b c}^{\mathrm{P}}=\mathbf{A}_{R_{I}}[\mathbf{I}]_{a b c}^{\mathrm{S}}\right.$

Eq. (54) is written in the same form as (12) so matrix $\mathbf{N}_{\mathrm{IV}_{a b c}}$ is already known:

$\mathbf{N}_{\mathrm{IV}_{\mathrm{abc}}}=\mathbf{A}_{R_{I}}$

In this case, Eq. (29) also applies, so matrix $\mathbf{N}_{\mathrm{III}}$ ibc is the same as in (28).

The four matrices $\mathbf{N}_{\mathrm{I} a b c}, \mathbf{N}_{\mathrm{II} a b c}, \mathbf{N}_{\mathrm{III} a b c}$ and $\mathbf{N}_{\mathrm{IV}_{a b c}}$ are included in Table 4 for both close delta connections (type A and B). All these matrices are defined again in terms of turns ratios, so they are the same for both raise and lower positions.

\subsubsection{Open-Delta connections}

Two single phase regulators can be connected giving rise to a three phase configuration. This is an open-Delta connection. Because there are two regulators to be connected between three phases, there are three different connections (or cases). In this work, the notation case $a$, case $b$ and case $c$ is going to be used. All configurations are depicted in Fig. 2e for type A regulators and in Fig. 2f for type B regulators. As in previous connections, the impedances are considered in the primary side for type $B$ and in the secondary side for type A regulators.

In Fig. 2e and f, characters $P_{1}, P_{2}, P_{3}, P_{1}^{\prime}, P_{2}^{\prime}$ and $P_{3}^{\prime}$ are used in the primary side and $s_{1}, s_{2}, s_{3}, s_{1}^{\prime}, s_{2}^{\prime}$ and $s_{3}^{\prime}$ denote secondary side. The schemes are general for all open delta configurations; the meaning of each character in both figures depends on the 
Table 2

Terminals notation for Open Delta connections.

\begin{tabular}{|c|c|c|c|c|c|c|}
\hline \multirow{2}{*}{$\begin{array}{l}\text { Regulators } \\
\text { Type }\end{array}$} & \multicolumn{2}{|c|}{$\begin{array}{l}\text { Case a } \\
\mathrm{ab} \& \mathrm{ca}\end{array}$} & \multicolumn{2}{|c|}{$\begin{array}{l}\text { Case b } \\
\text { bc \& ab }\end{array}$} & \multicolumn{2}{|c|}{$\begin{array}{l}\text { Case c } \\
\text { ca \& bc }\end{array}$} \\
\hline & A & B & A & B & A & B \\
\hline $\mathrm{P}_{1} \mathrm{P}_{2} \mathrm{P}_{3}$ & A B C & A B C & B C A & B C A & C A B & C A B \\
\hline $\mathrm{P}_{1}^{\prime} \mathrm{P}_{2}^{\prime} \mathrm{P}_{3}^{\prime}$ & - & $A^{\prime} B^{\prime} C^{\prime}$ & - & $\mathrm{B}^{\prime} \mathrm{C}^{\prime} \mathrm{A}^{\prime}$ & - & $C^{\prime} A^{\prime} B^{\prime}$ \\
\hline $\mathrm{s}_{1} \mathrm{~s}_{2} \mathrm{~s}_{3}$ & $\mathrm{a} b \mathrm{c}$ & $\mathrm{a} \mathrm{b} \mathrm{c}$ & $\mathrm{bc} \mathrm{a}$ & $b^{\prime} c^{\prime} a^{\prime}$ & $\mathrm{c} \mathrm{a} \mathrm{b}$ & $c^{\prime} a^{\prime} b^{\prime}$ \\
\hline$s_{1}^{\prime} s_{2}^{\prime} s_{3}^{\prime}$ & $a^{\prime} b^{\prime} c^{\prime}$ & - & $b^{\prime} c^{\prime} a^{\prime}$ & - & $c^{\prime} a^{\prime} b^{\prime}$ & - \\
\hline
\end{tabular}

considered case, as it is detailed in Table 2. For instance, in case $b$ the two regulators are connected between phases $b c$ and $a b$. As before, upper case letters are employed for the terminals at primary side and lower case letters are used for secondary side. The meaning of each character $P_{1}, P_{2}$ and $P_{3}$ are $B, C$ and $A$ respectively for both types of regulators; $P_{1}^{\prime}, P_{2}^{\prime}$ and $P_{3}^{\prime}$ mean $B^{\prime}, C^{\prime}$ and $A^{\prime}$ for type $\mathrm{B}$ regulators and has no meaning for type $\mathrm{A}$ because those points do not exist in open delta connected type $A$ regulators (see Fig. 2e).

In this section, the open-delta connection, case $a$ with type A regulators has been chosen as the case to explain the open-delta general model. The regulators are supposed to be in raise position. The matrices needed for the power flow problem are going to be deducted for this specific case, but with the general notation of Fig. $2 \mathrm{e}$ and $\mathrm{f}$ and Table 2 . The same reasoning may be applied to any other open-delta configuration.

First, it has to be noted for the studied configuration that phase $A$ in the primary and phase $a$ in the secondary are directly connected, so it can be written $A=a^{\prime}$. From Fig. 2e the voltages through the first regulator are related by:

$V_{a^{\prime} b^{\prime}}=V_{A b^{\prime}}=V_{A B}+V_{B b^{\prime}}$

Being $N_{1}$ the turns number for the shunt winding and $N_{2}$ the turns number for the series winding (in the regulator connected to phases $a b$ ), the voltages $V_{A B}$ and $V_{B b^{\prime}}$ can be related:

$\frac{V_{B b^{\prime}}}{V_{A B}}=\frac{N_{2}}{N_{1}}$

Merging (56) and (57) into one equation it is obtained:

$V_{a^{\prime} b^{\prime}}=V_{A B}+V_{A B} \frac{N_{2}}{N_{1}}=V_{A B}\left(1+\frac{N_{2}}{N_{1}}\right)$

Being the type $A$ regulators in raise position and according to Table 1, the equation becomes:

$V_{a^{\prime} b^{\prime}}=a_{R_{a b}} V_{A B}$

For voltage $V_{c^{\prime} a^{\prime}}$ the same procedure can be followed to obtain these expressions:

$V_{c^{\prime} a^{\prime}}=V_{c^{\prime} C}+V_{C A}$

$\frac{V_{C^{\prime} C}}{V_{C A}}=\frac{N_{2}}{N_{1}}$

$V_{C^{\prime} a^{\prime}}=V_{C A} \frac{N_{2}}{N_{1}}+V_{C A}$

$V_{C^{\prime} a^{\prime}}=V_{C A}\left(1+\frac{N_{2}}{N_{1}}\right)$

$V_{c^{\prime} a^{\prime}}=a_{R_{c a}} V_{C A}$

In matrix form, primary voltages as a function of secondary voltages are now obtained from the combination of (59) and (64) and taking into account that for three phase-three wire configurations the primary voltages have to satisfy $V_{A B}+V_{B C}+V_{C A}=0$.

$$
\left[\begin{array}{l}
V_{A B} \\
V_{B C} \\
V_{C A}
\end{array}\right]=\left(\begin{array}{ccc}
\frac{1}{a_{R_{a b}}} & 0 & 0 \\
-\frac{1}{a_{a b}} & 0 & -\frac{1}{a_{R_{c a}}} \\
0 & 0 & \frac{1}{a_{R_{c a}}}
\end{array}\right)\left[\begin{array}{l}
V_{a^{\prime} b^{\prime}} \\
V_{b^{\prime} c^{\prime}} \\
V_{c^{\prime} a^{\prime}}
\end{array}\right]
$$

The number of turns have been replaced by the effective turns ratios of the regulators, as it was done before.

If the same reasoning is carried out for lower positions, the matrix of (65) is also obtained. If this matrix is called $\mathbf{A}_{R_{v 2}}$, the equation can be written in compact form as:

$[\mathbf{V}]_{a b c}^{\mathrm{P}}=\mathbf{A}_{R_{v 2}}[\mathbf{V}]_{a b c}^{\mathrm{S}^{\prime}}$

For the studied connection, the drops across the secondary side impedances are given as:

$$
\left[\begin{array}{c}
V_{a^{\prime} a} \\
V_{b^{\prime} a} \\
V_{c^{\prime} c}
\end{array}\right]=Z\left(\begin{array}{lll}
0 & 0 & 0 \\
0 & 1 & 0 \\
0 & 0 & 1
\end{array}\right)\left[\begin{array}{c}
I_{a} \\
I_{b} \\
I_{c}
\end{array}\right]
$$

There is no voltage drop due to current $I_{a}$ because of the regulators connection (from Fig. 2e it easily deducted that $A=a=a^{\prime}$ ).

Eq. (42) must be also satisfied in this case, so the secondary voltages can be deducted merging Eqs. (42) and (67):

$\left[\begin{array}{c}V_{a^{\prime} b^{\prime}} \\ V_{b^{\prime} c^{\prime}} \\ V_{c^{\prime} a^{\prime}}\end{array}\right]=\left[\begin{array}{c}V_{a b} \\ V_{b c} \\ V_{c a}\end{array}\right]+Z \mathbf{T}_{\mathrm{DY}}\left(\begin{array}{lll}0 & 0 & 0 \\ 0 & 1 & 0 \\ 0 & 0 & 1\end{array}\right)\left[\begin{array}{c}I_{a} \\ I_{b} \\ I_{c}\end{array}\right]$

Substituting (68) into (65), and writing the new equation in compact form, it is obtained:

$[\mathbf{V}]_{a b c}^{\mathrm{P}}=\mathbf{A}_{R_{v 2}}[\mathbf{V}]_{a b c}^{\mathrm{S}}+Z \mathbf{A}_{R_{v 2}} \mathbf{T}_{\mathrm{DY} a}[\mathbf{I}]_{a b c}^{\mathrm{S}}$

where

$\mathbf{T}_{\mathrm{DY} a}=\left(\begin{array}{rrr}0 & -1 & 0 \\ 0 & 1 & -1 \\ 0 & 0 & 1\end{array}\right)$

Matrix $\mathbf{T}_{\mathrm{DY} a}$ in (70) is the same matrix as $\mathbf{T}_{\mathrm{DY}}$ in (43) in which the first column was replaced by zeros. For open-delta configurations case $b$ and case $c$, the matrices $\mathbf{T}_{\mathrm{DY} b}$ and $\mathbf{T}_{\mathrm{DY} c}$ would be obtained. In the former, the second column in $\mathbf{T}_{\mathrm{DY}}$ has been replaced by zeros and in the latter the third column in $\mathbf{T}_{\mathrm{DY}}$ is changed by zeros.

To derive the relationship between primary and secondary currents in Fig. 2e, the depicted current references as well as the corresponding phases related in Table 2 are needed. From the figure it can be said:

$I_{B}=I_{b}+I_{B A}$

$I_{C}=I_{C}+I_{C A}$

If for both regulators the numbers of turns are $N_{1}$ and $N_{2}$ for the shunt and series wingdings respectively and the raise position is considered, then it can be assured that: 
$\frac{I_{B A}}{I_{b}}=\frac{N_{2}}{N_{1}}$

$\frac{I_{C A}}{I_{C}}=\frac{N_{2}}{N_{1}}$

Merging the last four equations, and writing them in terms of turns relations, it is obtained that:

$I_{B}=I_{b}\left(1+\frac{N_{2}}{N_{1}}\right)=a_{R_{a b}} I_{b}$

$I_{C}=I_{c}\left(1+\frac{N_{2}}{N_{1}}\right)=a_{R_{c a}} I_{c}$

Merging (75) and (76) and taking into account that for a three phase three wire connection the equation $I_{A}+I_{B}+I_{C}=0$ must be satisfied, a matrix equation is obtained:

$$
\left[\begin{array}{c}
I_{A} \\
I_{B} \\
I_{C}
\end{array}\right]=\left(\begin{array}{ccc}
0 & -a_{R_{a b}} & -a_{R_{c a}} \\
0 & a_{R_{a b}} & 0 \\
0 & 0 & a_{R_{c a}}
\end{array}\right)\left[\begin{array}{c}
I_{a} \\
I_{b} \\
I_{c}
\end{array}\right]
$$

Being the matrix in Eq. (77) named as $\mathbf{A}_{R_{12}}$, this equation if of the same form as (12):

$[\mathbf{I}]_{a b c}^{\mathrm{P}}=\mathbf{A}_{R_{12}}[\mathbf{I}]_{a b c}^{\mathrm{S}}$

Then, matrix $\mathbf{N}_{\mathrm{IV}_{a b c}}$ can be obtained:

$\mathbf{N}_{\mathrm{IV}_{a b c}}=\mathbf{A}_{R_{l 2}}$

In this case, Eq. (29) also applies, so matrix $\mathbf{N}_{\mathrm{III} a b c}$ is the same matrix as in (28).

Matrices $\mathbf{N}_{\mathrm{I}_{a b c}}, \mathbf{N}_{\mathrm{II}}, \mathbf{N}_{\mathrm{II}}$ abc and $\mathbf{N}_{\mathrm{IV}}$ abc are included in Table 4 for all open delta configurations (cases $a, b$ and $c$, type $\mathrm{A}$ and $\mathrm{B}$ regulators). They are defined in terms of effective turns ratios, so they are the same for both raise and lower positions. To obtain the corresponding $\alpha \beta 0$ frame matrices, the same transformation that was used for previous connections may be applicable (32).

With the generalized matrices detailed in Table 4, the SVR models are prepared for the power flow solver. All the configurations in the table were simulated in the 4-Node Test Feeder, as it will be explained later.

\subsection{Comparison to previous works}

There are several related works in the literature that present similar SVR models, however, none of them includes all possible configurations. In Table 3 a comparison to the models described in previous works is summarized. It can be seen how the type B regulators are usually considered due to the fact they are mainly installed in the distribution systems. With our work we aim to include not only the most common configurations, but all of them; We describe and propose a general model that will allow the inclusion any SVR configuration in a power flow analysis. Besides, a 4-Node Test Feeder with SVR is provided.

Table 3

Comparison to previous modeling works.

\begin{tabular}{cccc}
\hline Refs. & Connection & Type & Frame \\
\hline$[9]$ & $\mathbf{O \Delta}$ & not specified & abc \\
{$[11]$} & $\mathbf{Y Y}$ & B & abc \\
{$[16]$} & $\mathbf{Y Y}$ & B & abc \\
{$[20]$} & $\mathbf{O \Delta}$, case b & B & abc \\
{$[26]$} & $\mathbf{Y Y}$ & B & abc \\
{$[27]$} & $\mathbf{Y Y}, \boldsymbol{\Delta} \boldsymbol{\Delta}, \mathbf{O} \boldsymbol{\Delta}$, case b & B & abc \\
Present work & All & A and B & abc $/ \alpha \beta 0$ \\
\hline
\end{tabular}

\section{4-Node Test Feeder including SVRs}

To introduce SVRs in the 4-Node Test Feeder [28], the transformer was replaced by a SVR. The power flow problem to be solved is the one in which the transformer matrices $\mathbf{N}_{\text {I }}, \mathbf{N}_{\text {II }}, \mathbf{N}_{\text {III }}$ and $\mathbf{N}_{\text {IV }}$ are taken from Table 4 for each specific SVR configuration. The matrices in this table are defined in $a b c$ frame, so they need to be translated into $\alpha \beta 0$ frame by means of Eq. (32).

Several configurations were solved for defining a benchmark of results. The effective turns ratios for the different regulators were taken considering that most of the SVRs have a reversing switch enabling $\pm 10 \%$ regulator range in 32 steps (16 in raise and 16 in lower positions). That means a change of 0.625 per unit per step. With these numbers, the effective turns ratio in terms of number of turns might be replaced by expression [27, Chapter 7]:

$a_{R}=1 \oplus 0.00625$ Tap

where Tap has a value between 0 and 16, depending on the tap position and the operator $\oplus$ has to be taken from Table 1 . The model has been defined in such a way that for wye and close-delta configurations three single phase regulators are connected together. That means the taps of each regulator can change separately. This implies different values for the effective turns ratio per phase. Nevertheless, three phase regulators (in which the taps in all windings change the same) might be also modeled by choosing the same values of $a_{R}$ in the three phases. For open delta connections only single phase regulators are used, so the values for the different turns ratio $a_{R}$ can be equal or not.

The resulting 4-Node Test Feeder including a SVR is depicted in Fig. 3. The SVR is always connected between nodes 2 and 3, node 1 works as an infinite or slack bus and the load is connected at node 4. Line configurations and load types were chosen from the conventional test feeder [28]. In this case, because the transformer has been replaced by a SVR the rated voltage is the same in primary and secondary sides of the regulator. This value has been chosen as $12.47 \mathrm{kV}$ that is one of the rated voltages at load side in the original test feeder.

The used algorithm is an unbalanced BFS solver [27] in which linear equations were defined in matrix form including all system KVL and KCL equations:

$\mathbf{M z}^{T}=0$

The vector $\mathbf{z}$ contains all complex, three phase system voltages and currents as follows:

$\mathbf{Z}=\left[\begin{array}{lllllllll}\mathbf{I}_{12} & \mathbf{I}_{23} & \mathbf{I}_{34} & \mathbf{I}_{\mathbf{L o a d}_{4}} & \mathbf{I}_{\mathbf{G}_{1}} & \mathbf{V}_{1} & \mathbf{V}_{2} & \mathbf{V}_{3} & \mathbf{V}_{4}\end{array}\right]_{\alpha \beta 0}$

where $\mathbf{I}_{12}$ and $\mathbf{I}_{34}$ are the line currents depicted in Fig. $3, \mathbf{I}_{G_{1}}$ are the currents from the infinite bus (the only generator), $\mathbf{I}_{\text {Load }_{4}}$ are the load currents and $\mathbf{I}_{23}$ are the SVR primary or secondary currents depending on its configuration. The structure of $\mathbf{M}$ is shown in (83).

$$
\mathbf{M}=\left(\begin{array}{c|c|c|c}
\mathbf{Z}_{\alpha \beta 0} & 0 & 0 & -\boldsymbol{\Gamma} \\
\hline \boldsymbol{\Gamma}^{T} & \mathbf{I}_{d} & -\mathbf{I}_{d} & 0
\end{array}\right)
$$

where the matrices $\boldsymbol{\Gamma}$ and $\boldsymbol{\Gamma}^{\boldsymbol{T}}$ are the modified node incidence matrices in which the SVR matrices $\mathbf{N}_{\mathrm{I}}, \mathbf{N}_{\mathrm{II}}, \mathbf{N}_{\mathrm{III}}$ and $\mathbf{N}_{\mathrm{IV}}$ are included at the corresponding positions where a SVR is connected. This is the same procedure that the one for transformers described in [30].

The load will add the following non-linear equations:

$\mathbf{P}_{a b c}=\operatorname{real}\left(\mathbf{A V}_{\alpha \beta \beta 0} \circ \operatorname{conj}\left[\mathbf{A I}_{L_{\alpha \beta 0}}\right]\right)$

$\mathbf{Q}_{a b c}=\operatorname{imag}\left(\mathbf{A} \mathbf{V}_{\alpha \beta 0} \circ \operatorname{conj}\left[\mathbf{A I}_{L_{\alpha \beta 0}}\right]\right)$

where the operator $\circ$ is the Hadamard (element-wise) product. 
Table 4

Matrices for all SVR configurations.

\begin{tabular}{|c|c|c|c|c|c|}
\hline & \multicolumn{2}{|l|}{$\mathbf{N}_{I_{a b c}}$} & $\mathbf{N}_{\mathrm{II}_{a b c}}$ & $\mathbf{N}_{\mathrm{III}_{a b c}}$ & $\mathbf{N}_{\mathrm{IV}_{a b c}}$ \\
\hline $\begin{array}{c}\text { YY } \\
\text { type A }\end{array}$ & $\left(\begin{array}{ccc}\frac{1}{a_{R_{a}}} & 0 & 0 \\
0 & \frac{1}{a_{R_{b}}} & 0 \\
0 & 0 & \frac{1}{a_{R_{c}}}\end{array}\right)$ & & $\left(\begin{array}{ccc}\frac{1}{a_{R_{a}}} & 0 & 0 \\
0 & \frac{1}{a_{R_{b}}} & 0 \\
0 & 0 & \frac{1}{a_{R_{c}}}\end{array}\right)$ & $-\mathbf{I}_{d(3 \times 3)}$ & $\left(\begin{array}{ccc}a_{R_{a}} & 0 & 0 \\
0 & a_{R_{b}} & 0 \\
0 & 0 & a_{R_{c}}\end{array}\right)$ \\
\hline $\begin{array}{c}\text { YY } \\
\text { type B }\end{array}$ & \multicolumn{2}{|l|}{$\mathbf{I}_{d(3 \times 3)}$} & $\left(\begin{array}{ccc}a_{R_{a}} & 0 & 0 \\
0 & a_{R_{b}} & 0 \\
0 & 0 & a_{R_{c}}\end{array}\right)$ & $-\left(\begin{array}{ccc}a_{R_{a}} & 0 & 0 \\
0 & a_{R_{b}} & 0 \\
0 & 0 & a_{R_{c}}\end{array}\right)$ & $\mathbf{I}_{d(3 \times 3)}$ \\
\hline $\begin{array}{c}\Delta \Delta \\
\text { type A }\end{array}$ & $\left(\begin{array}{ccc}a_{R_{a b}} & 1-a_{R_{b c}} & 0 \\
0 & a_{R_{b c}} & 1-a_{R_{c a}} \\
1-a_{R_{a b}} & 0 & a_{R_{c a}}\end{array}\right)$ & $\int^{-1} \cdot \mathbf{T}_{\mathbf{D Y}}$ & $\left(\begin{array}{ccc}a_{R_{a b}} & 1-a_{R_{b c}} & 0 \\
0 & a_{R_{b c}} & 1-a_{R_{c a}} \\
1-a_{R_{a b}} & 0 & a_{R_{c a}}\end{array}\right)^{-}$ & $-\mathbf{I}_{d(3 \times 3)}$ & $\left(\begin{array}{ccc}a_{R_{a b}} & 0 & 1-a_{R_{c a}} \\
1-a_{R_{a b}} & a_{R_{b c}} & 0 \\
0 & 1-a_{R_{b c}} & a_{R_{c a}}\end{array}\right)$ \\
\hline$\underset{\text { type B }}{\Delta \Delta}$ & \multicolumn{2}{|l|}{$\mathbf{T}_{\mathbf{D Y}}$} & $\left(\begin{array}{ccc}a_{R_{a b}} & 1-a_{R_{b c}} & 0 \\
0 & a_{R_{b c}} & 1-a_{R_{c a}} \\
1-a_{R_{a b}} & 0 & a_{R_{c a}}\end{array}\right)$ & $-\left(\begin{array}{ccc}a_{R_{a b}} & 0 & 1-a_{R_{c a}} \\
1-a_{R_{a b}} & a_{R_{b c}} & 0 \\
0 & 1-a_{R_{b c}} & a_{R_{c a}}\end{array}\right)$ & $\mathbf{I}_{d(3 \times 3)}$ \\
\hline $\begin{array}{c}\mathrm{O \Delta} \\
\text { type A } \\
\text { case a }\end{array}$ & $\left(\begin{array}{ccc}\frac{1}{{ }^{a} R_{a b}} & 0 & 0 \\
-\frac{1}{{ }^{a} R_{a b}} & 0 & -\frac{1}{{ }^{a} R_{c a}} \\
0 & 0 & \frac{1}{{ }^{a} R_{c a}}\end{array}\right)$ & $\mathbf{T}_{\mathbf{D Y} a}$ & $\left(\begin{array}{ccc}\frac{1}{a_{R_{a b}}} & 0 & 0 \\
-\frac{1}{a^{a} R_{a b}} & 0 & -\frac{1}{a^{a} R_{c a}} \\
0 & 0 & \frac{1}{{ }^{a} R_{c a}}\end{array}\right)$ & $-\mathbf{I}_{d(3 \times 3)}$ & $\left(\begin{array}{ccc}0 & -a_{R_{a b}} & -a_{R_{c a}} \\
0 & a_{R_{a b}} & 0 \\
0 & 0 & a_{R_{c a}}\end{array}\right)$ \\
\hline $\begin{array}{l}\mathrm{OA} \\
\text { type A } \\
\text { case b }\end{array}$ & $\left(\begin{array}{ccc}\frac{1}{{ }^{a} R_{a b}} & 0 & 0 \\
0 & \frac{1}{{ }^{a} R_{b c}} & 0 \\
-\frac{1}{{ }^{a} R_{a b}} & -\frac{1}{{ }^{a} R_{b c}} & 0\end{array}\right)$. & $\mathbf{T}_{\mathbf{D Y} b}$ & $\left(\begin{array}{ccc}\frac{1}{{ }^{a} R_{a b}} & 0 & 0 \\
0 & \frac{1}{a^{a} R_{b c}} & 0 \\
-\frac{1}{a^{a} R_{a b}} & -\frac{1}{{ }^{a} R_{b c}} & 0\end{array}\right)$ & $-\mathbf{I}_{d(3 \times 3)}$ & $\left(\begin{array}{ccc}a_{R_{a b}} & 0 & 0 \\
-a_{R_{a b}} & 0 & -a_{R_{b c}} \\
0 & 0 & a_{R_{b c}}\end{array}\right)$ \\
\hline $\begin{array}{l}\mathrm{O \Delta} \\
\text { type A } \\
\text { case c }\end{array}$ & $\left(\begin{array}{ccc}0 & -\frac{1}{a_{R_{b c}}} & -\frac{1}{a_{R_{c a}}} \\
0 & \frac{1}{a_{R_{b c}}} & 0 \\
0 & 0 & \frac{1}{{ }^{a} R_{c a}}\end{array}\right)$ &. $\mathbf{T}_{\mathbf{D Y}} \mathbf{Y}_{c}$ & $\left(\begin{array}{ccc}0 & -\frac{1}{a_{R_{b c}}} & -\frac{1}{a_{R_{c a}}} \\
0 & \frac{1}{{ }^{a} R_{b c}} & 0 \\
0 & 0 & \frac{1}{{ }^{a} R_{c a}}\end{array}\right)$ & $-\mathbf{I}_{d(3 \times 3)}$ & $\left(\begin{array}{ccc}a_{R_{b c}} & 0 & 0 \\
0 & a_{R_{c b}} & 0 \\
-a_{R_{b c}} & -a_{R_{c a}} & 0\end{array}\right)$ \\
\hline $\begin{array}{l}\mathrm{OA} \\
\text { type } \mathrm{B} \\
\text { case a }\end{array}$ & $\mathbf{T}_{\mathbf{D Y} a}$ & & $\left(\begin{array}{ccc}a_{R_{a b}} & 0 & 0 \\
-a_{R_{a b}} & 0 & -a_{R_{c a}} \\
0 & 0 & a_{R_{c a}}\end{array}\right)$ & $-\left(\begin{array}{ccc}0 & -\frac{1}{a_{R_{a b}}} & -\frac{1}{a_{R_{c a}}} \\
0 & \frac{1}{a_{a b}} & 0 \\
0 & 0 & \frac{1}{a_{R_{c a}}}\end{array}\right)$ & $\mathbf{I}_{d(3 \times 3)}$ \\
\hline $\begin{array}{l}\mathrm{O \Delta} \\
\text { type } B \\
\text { case } \mathrm{b}\end{array}$ & $\mathbf{T}_{\mathbf{D Y} b}$ & & $\left(\begin{array}{ccc}a_{R_{a b}} & 0 & 0 \\
0 & a_{R_{b c}} & 0 \\
-a_{R_{a b}} & -a_{R_{b c}} & 0\end{array}\right)$ & $-\left(\begin{array}{ccc}\frac{1}{{ }^{a} R_{a b}} & 0 & 0 \\
-\frac{1}{a_{R_{a b}}} & 0 & -\frac{1}{a_{R_{b c}}} \\
0 & 0 & \frac{1}{{ }^{a} R_{b c}}\end{array}\right)$ & $\mathbf{I}_{d(3 \times 3)}$ \\
\hline $\begin{array}{l}\mathrm{O} \Delta \\
\text { type } B \\
\text { case c }\end{array}$ & $\mathbf{T}_{\mathbf{D Y}}{ }_{c}$ & & $\left(\begin{array}{ccc}0 & -a_{R_{b c}} & -a_{R_{c a}} \\
0 & a_{R_{b c}} & 0 \\
0 & 0 & a_{R_{c a}}\end{array}\right)$ & $-\left(\begin{array}{ccc}\frac{1}{a_{R_{c a}}} & 0 & 0 \\
0 & \frac{1}{a_{R_{b c}}} & 0 \\
-\frac{1}{a_{R_{c a}}} & -\frac{1}{{ }^{a_{R_{b c}}}} & 0\end{array}\right)$ & $\mathbf{I}_{d(3 \times 3)}$ \\
\hline
\end{tabular}

Where $\boldsymbol{\Delta}$ stands for Delta $\mathbf{Y}$ for wye and $\mathbf{0} \Delta$ for Open Delta.

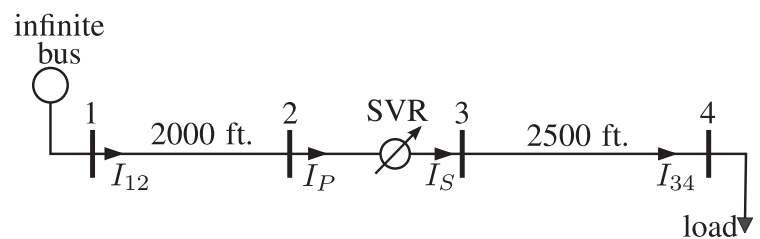

Fig. 3. 4 Node Test Feeder system.

To test the different configurations for the regulators in lower and raise positions, both types of loads; capacitive and inductive were considered. In all studied cases the algorithm has shown good convergence.

Due to the extension of this paper and the lack of space that would be necessary to properly describe and present all cases, this manuscript presents some examples. Additional results will be available on-line (see Supplementary material).

\section{Basic data}

The data for describing loads, lines and SVR were chosen similar to those described in the 4-Node Test Feeder with transformers
[28] but with some modifications needed to replace the transformer by a SVR.

\subsection{Step Voltage Regulators}

The SVR configurations used in this work were taken from [27, chapter 7]. Depending on the way that the single-phase regulators are connected, the resulting configurations are different. In wye and close delta there are 3 regulators, but in case of open delta there are only 2 regulators. In open delta, 3 different connections (cases a, b and c) are defined: In case a, the regulators are connected to phases $a b$ and $c a$, in case $b$ to phases $a b$ and $c a$ and finally, in case $c$ to phases $a b$ and ca. There is only a four-wire configuration: wye-grounded connection; Close delta and open delta are three-wire. That means the lines connected to a wye-grounded SVR have to be four-wire and in the other four cases they have to be three-wire configured.

The 3-phase SVR has rated values as follows: Power of 6000 $\mathrm{kVA}$; voltage $12.47 \mathrm{kV} ; \mathrm{R}=1 \%$ and $\mathrm{X}=6 \%$.

\subsection{Loads}

A 3-phase load is connected to node 4. Depending on the SVR connection and the line configuration between nodes 3 and 4 , 
Table 5

Loads.

\begin{tabular}{rrrr}
\hline & & \multicolumn{1}{c}{ Balanced } & Unbalanced \\
\hline Phase 1 & $\mathrm{P}(\mathrm{kW})$ & 1800 & 1275 \\
& Power factor & $0.9 \mathrm{lag} / \mathrm{lead}$ & $0.85 \mathrm{lag} / \mathrm{lead}$ \\
Phase 2 & $\mathrm{P}(\mathrm{kW})$ & 1800 & 1800 \\
& Power factor & $0.9 \mathrm{lag} / \mathrm{lead}$ & $0.9 \mathrm{lag} / \mathrm{lead}$ \\
Phase 3 & P (kW) & 1800 & 2375 \\
& Power factor & $0.9 \mathrm{lag} / \mathrm{lead}$ & $0.95 \mathrm{lag} / \mathrm{lead}$ \\
\hline
\end{tabular}

the load is wye-grounded or delta type. Loads are given in terms of constant active and reactive power (PQ). Different loading scenarios were considered trying to achieve different positions in taps (raise and lower positions). The loads are defined in Table 5. For each balanced or unbalanced loading scenario two possibilities are considered: lag and lead power factor. In the table, there is no reference to phases a, b and c as the nomenclature phase 1,2 and 3 is employed instead. This is because the spot loads are not always connected to a given phase: For 3-wire nodes loads are connected line-to-line and for 4-wire nodes the loads are connected between a phase and the neutral conductor.

\subsection{Lines}

The lines were chosen to be exactly the same configurations and lengths as in the 4-Node Test Feeder.

The line model is the exact segment model described in [27, chapter 6]. The matrices derived from Carson's equations and Kron's reduction are always of dimensions $3 \times 3$ and are available in the web site [28] for both three-wire and four-wire configurations.

\section{Study cases}

The cases have been selected in such a way that each SVR configuration (type A and type B regulators) has been tested under several conditions: Balanced and unbalanced, inductive (lag power factor) and capacitive (lead power factor) loading and two different cases: Before and after optimization. The optimization has to do with tap positions; Each regulator has 32 taps; The neutral position is in the middle, there are 16 taps for raise positions and other 16 taps for lower positions. Before and after optimization refer to the comparison between two different scenarios: The first one with the SVR in the neutral position, and the second scenario with regulation to achieve the minimum value in voltage magnitude for the whole grid, without violating the voltage constraint.

The load can be inductive or capacitive, so the taps will need to be sometimes in raise and other times in lower positions. The different combinations between connections, regulator types and loading scenarios, as well as the cases before/after optimization have given rise to 80 different cases.

For wye and close delta connections there are 3 taps per regulator, that can be changed independently, but in case of open delta there are only 2 tap changers per regulator, that means one less grade of freedom for optimization.

For the voltage constraint, 0.95 per unit was selected as the minimum voltage. That means $11847 \mathrm{~V}$ phase-to-phase or $6840 \mathrm{~V}$ phase-to-neutral. There was no need of fixing a maximum value, because the optimization aims to find the minimum voltage profile that satisfies the constraint, so the maximum value is never reached.

Because the system is radial, the furthest node from the slack is node 4 . As a result, it happened for all inductive loading scenarios that the minimum voltage magnitudes are obtained at that node, so if the minimum voltage constraint is satisfied at this node it will be satisfied at all nodes. Then, it is expected that the optimization algorithm searches for a power flow solution that meets the minimum voltage profile per phase $(0.95 \mathrm{pu})$ at node 4 in inductive cases. For capacitive loading cases the voltage profile changes because node 4 does not always present the minimum voltage per phase in the network.

\section{Results}

The results to the 80 cases are available on line (16 tables in total; see Supplementary material). They have been organized in tables. Two examples of them are included in here: Tables 6 and 7. They include three phase voltages in nodes 2, 3 and 4 and three phase currents in lines 1 (from node 1 to 2 ) and line 2 (from node 3 to 4). The currents are line currents in phases a, b and $c$ while the voltages are line-to-line voltages for 3-wire nodes and line-to-neutral voltages for 4-wire nodes. Each single current or voltage is represented by its magnitude in Amps or Volts and its phase in degrees. The columns correspond to the different connections: $\mathrm{Y}_{g} \mathrm{Y}_{g}, \Delta \Delta$ and $\mathrm{O} \Delta$ stand for wye grounded, close delta and open delta respectively. All the results in a table correspond to the same loading scenario (in this case balanced and inductive loading case) and the same optimization stage (before and after optimization in these two tables).

Table 6

Type A regulators. Inductive balanced loading. Before Optimization.

\begin{tabular}{|c|c|c|c|c|c|c|}
\hline & \multirow[b]{2}{*}{ Taps } & $\mathrm{Y}_{g} \mathrm{Y}_{g}$ & $\Delta \Delta$ & $\mathrm{O} \Delta$ case $\mathrm{a}$ & $\mathrm{O} \Delta$ case $\mathrm{b}$ & \multirow{2}{*}{$\begin{array}{l}\mathrm{O} \Delta \text { case } \mathrm{c} \\
{\left[\begin{array}{lll}- & 0 & 0\end{array}\right]}\end{array}$} \\
\hline & & {$\left[\begin{array}{lll}0 & 0 & 0\end{array}\right]$} & {$\left[\begin{array}{lll}0 & 0 & 0\end{array}\right]$} & {$[0-0]$} & {$\left[\begin{array}{lll}0 & 0 & -\end{array}\right]$} & \\
\hline Node 2 & $\begin{array}{l}V_{1} \\
V_{2} \\
V_{3}\end{array}$ & $\begin{array}{l}7125 \angle-0.3^{\circ} \\
7145 \angle-120.4^{\circ} \\
7136 \angle 119.6^{\circ}\end{array}$ & $\begin{array}{l}12360 \angle 29.7^{\circ} \\
12370 \angle-120.4^{\circ} \\
12346 \angle 149.6^{\circ}\end{array}$ & $\begin{array}{l}12364 \angle 29.7^{\circ} \\
12375 \angle-90.4^{\circ} \\
12351 \angle 149.6^{\circ}\end{array}$ & $\begin{array}{l}12365 \angle 29.7^{\circ} \\
12376 \angle-90.4^{\circ} \\
12353 \angle 149.6^{\circ}\end{array}$ & $\begin{array}{l}12362 \angle 29.7^{\circ} \\
12373 \angle-90.4^{\circ} \\
12349 \angle 149.6^{\circ}\end{array}$ \\
\hline Node 3 & $\begin{array}{l}V_{1} \\
V_{2} \\
V_{3}\end{array}$ & $\begin{array}{l}6842 \angle-3.4^{\circ} \\
6863 \angle-123.4^{\circ} \\
6854 \angle 116.6^{\circ}\end{array}$ & $\begin{array}{l}11870 \angle 26.7^{\circ} \\
11882 \angle-93.4^{\circ} \\
11857 \angle 146.6^{\circ}\end{array}$ & $\begin{array}{l}12364 \angle 29.7^{\circ} \\
12125 \angle-93.0^{\circ} \\
11749 \angle 149.4^{\circ}\end{array}$ & $\begin{array}{l}11951 \angle 28.8^{\circ} \\
12194 \angle-89.8^{\circ} \\
12330 \angle 148.6^{\circ}\end{array}$ & $\begin{array}{l}11891 \angle 26.7^{\circ} \\
11950 \angle-91.2^{\circ} \\
12296 \angle 147.5^{\circ}\end{array}$ \\
\hline Node 4 & $\begin{array}{l}V_{1} \\
V_{2} \\
V_{3}\end{array}$ & $\begin{array}{l}6752 \angle-3.8^{\circ} \\
6798 \angle-123.9^{\circ} \\
6778 \angle 116.0^{\circ}\end{array}$ & $\begin{array}{l}11737 \angle 26.3^{\circ} \\
11764 \angle-94.0^{\circ} \\
11709 \angle 146.0^{\circ}\end{array}$ & $\begin{array}{l}12231 \angle 29.3^{\circ} \\
12012 \angle-93.5^{\circ} \\
11601 \angle 148.9^{\circ}\end{array}$ & $\begin{array}{l}11821 \angle 28.4^{\circ} \\
12077 \angle-90.3^{\circ} \\
12187 \angle 148.0^{\circ}\end{array}$ & $\begin{array}{l}11762 \angle 26.3^{\circ} \\
11832 \angle-91.8^{\circ} \\
12150 \angle 147.0^{\circ}\end{array}$ \\
\hline Line 12 & $\begin{array}{l}I_{a} \\
I_{b} \\
I_{c}\end{array}$ & $\begin{array}{l}296.2 \angle-29.7^{\circ} \\
294.2 \angle-149.7^{\circ} \\
295.1 \angle 90.2^{\circ}\end{array}$ & $\begin{array}{l}295.2 \angle-29.7^{\circ} \\
295.2 \angle-149.7^{\circ} \\
295.2 \angle 90.3^{\circ}\end{array}$ & $\begin{array}{l}290.3 \angle-27.6^{\circ} \\
289.8 \angle-147.7^{\circ} \\
290.0 \angle 92.4^{\circ}\end{array}$ & $\begin{array}{l}288.1 \angle-27.1^{\circ} \\
288.0 \angle-147.1^{\circ} \\
288.0 \angle 92.9^{\circ}\end{array}$ & $\begin{array}{l}290.9 \angle-28.7^{\circ} \\
290.7 \angle-148.7^{\circ} \\
290.8 \angle 91.4^{\circ}\end{array}$ \\
\hline Line 34 & $\begin{array}{l}I_{a} \\
I_{b} \\
I_{c}\end{array}$ & $\begin{array}{l}296.2 \angle-29.7^{\circ} \\
294.2 \angle-149.7^{\circ} \\
295.1 \angle 90.2^{\circ}\end{array}$ & $\begin{array}{l}295.2 \angle-29.7^{\circ} \\
295.2 \angle-149.7^{\circ} \\
295.2 \angle 90.3^{\circ}\end{array}$ & $\begin{array}{l}290.3 \angle-27.6^{\circ} \\
289.8 \angle-147.7^{\circ} \\
290.0 \angle 92.4^{\circ}\end{array}$ & $\begin{array}{l}288.1 \angle-27.1^{\circ} \\
288.0 \angle-147.1^{\circ} \\
288.0 \angle 92.9^{\circ}\end{array}$ & $\begin{array}{l}290.9 \angle-28.7^{\circ} \\
290.7 \angle-148.7^{\circ} \\
290.8 \angle 91.4^{\circ}\end{array}$ \\
\hline
\end{tabular}

Where $V_{1}, V_{2}$ and $V_{3}$ are phase to neutral voltages in wye connections and phase to ground voltages in the others. 
Table 7

Type A regulators. Inductive balanced loading. After Optimization

\begin{tabular}{|c|c|c|c|c|c|c|}
\hline & \multirow[b]{2}{*}{ Taps } & $\mathrm{Y}_{g} \mathrm{Y}_{g}$ & $\Delta \Delta$ & $\mathrm{O} \Delta$ case $\mathrm{a}$ & $\mathrm{O} \Delta$ case $\mathrm{b}$ & \multirow{2}{*}{$\begin{array}{l}\text { O } \Delta \text { case } c \\
{\left[\begin{array}{lll}- & 1 & 2\end{array}\right]}\end{array}$} \\
\hline & & {$\left[\begin{array}{lll}2 & 1 & 2\end{array}\right]$} & {$\left[\begin{array}{lll}2 & 1 & 2\end{array}\right]$} & {$\left[\begin{array}{lll}-5 & - & 4\end{array}\right]$} & {$\left[\begin{array}{lll}1 & -3 & -\end{array}\right]$} & \\
\hline Node 2 & $\begin{array}{l}V_{1} \\
V_{2} \\
V_{3}\end{array}$ & $\begin{array}{l}7125 \angle-0.3^{\circ} \\
7145 \angle-120.3^{\circ} \\
7136 \angle 119.6^{\circ}\end{array}$ & $\begin{array}{l}12360 \angle 29.7^{\circ} \\
12371 \angle-90.4^{\circ} \\
12346 \angle 149.6^{\circ}\end{array}$ & $\begin{array}{l}12365 \angle 29.7^{\circ} \\
12377 \angle-90.4^{\circ} \\
12347 \angle 149.6^{\circ}\end{array}$ & $\begin{array}{l}12363 \angle 29.7^{\circ} \\
12377 \angle-90.4^{\circ} \\
12354 \angle 149.6^{\circ}\end{array}$ & $\begin{array}{l}12362 \angle 29.7^{\circ} \\
12373 \angle-90.4^{\circ} \\
12349 \angle 149.6^{\circ}\end{array}$ \\
\hline Node 3 & $\begin{array}{l}V_{1} \\
V_{2} \\
V_{3}\end{array}$ & $\begin{array}{l}6936 \angle-3.3^{\circ} \\
6910 \angle-123.3^{\circ} \\
6947 \angle 116.7^{\circ}\end{array}$ & $\begin{array}{l}12075 \angle 27.1^{\circ} \\
12046 \angle-92.7^{\circ} \\
12098 \angle 147.3^{\circ}\end{array}$ & $\begin{array}{l}11979 \angle 29.7^{\circ} \\
12070 \angle-90.2^{\circ} \\
12040 \angle 149.4^{\circ}\end{array}$ & $\begin{array}{l}12025 \angle 28.8^{\circ} \\
11965 \angle-89.8^{\circ} \\
12253 \angle 149.8^{\circ}\end{array}$ & $\begin{array}{l}12015 \angle 26.4^{\circ} \\
12031 \angle-91.2^{\circ} \\
12450 \angle 147.6^{\circ}\end{array}$ \\
\hline Node 4 & $\begin{array}{l}V_{1} \\
V_{2} \\
V_{3}\end{array}$ & $\begin{array}{l}6847 \angle-3.7^{\circ} \\
6845 \angle-123.8^{\circ} \\
6873 \angle 116.1^{\circ}\end{array}$ & $\begin{array}{l}11944 \angle 26.7^{\circ} \\
11930 \angle-93.2^{\circ} \\
11952 \angle 146.8^{\circ}\end{array}$ & $\begin{array}{l}11847 \angle 29.3^{\circ} \\
11953 \angle-90.7^{\circ} \\
11894 \angle 148.9^{\circ}\end{array}$ & $\begin{array}{l}11895 \angle 28.4^{\circ} \\
11848 \angle-90.3^{\circ} \\
12107 \angle 149.2^{\circ}\end{array}$ & $\begin{array}{l}11887 \angle 26.0^{\circ} \\
11914 \angle-91.7^{\circ} \\
12305 \angle 147.0^{\circ}\end{array}$ \\
\hline Line 12 & $\begin{array}{l}I_{a} \\
I_{b} \\
I_{c}\end{array}$ & $\begin{array}{l}295.8 \angle-29.6^{\circ} \\
294.0 \angle-149.7^{\circ} \\
294.6 \angle 90.3^{\circ}\end{array}$ & $\begin{array}{l}295.5 \angle-29.7^{\circ} \\
293.7 \angle-149.7^{\circ} \\
294.6 \angle 90.6^{\circ}\end{array}$ & $\begin{array}{l}290.6 \angle-29.5^{\circ} \\
282.1 \angle-146.7^{\circ} \\
298.4 \angle 93.3^{\circ}\end{array}$ & $\begin{array}{l}291.7 \angle-26.7^{\circ} \\
288.1 \angle-148.0^{\circ} \\
284.5 \angle 93.3^{\circ}\end{array}$ & $\begin{array}{l}289.8 \angle-28.8^{\circ} \\
291.3 \angle-148.7^{\circ} \\
290.6 \angle 91.0^{\circ}\end{array}$ \\
\hline Line 34 & $\begin{array}{l}I_{a} \\
I_{b} \\
I_{c}\end{array}$ & $\begin{array}{l}292.1 \angle-29.6^{\circ} \\
292.2 \angle-149.7^{\circ} \\
291.0 \angle 90.3^{\circ}\end{array}$ & $\begin{array}{l}290.1 \angle-29.1^{\circ} \\
290.1 \angle-149.1^{\circ} \\
290.1 \angle 90.9^{\circ}\end{array}$ & $\begin{array}{l}291.1 \angle-29.7^{\circ} \\
291.2 \angle-146.7^{\circ} \\
291.1 \angle 93.3^{\circ}\end{array}$ & $\begin{array}{l}289.9 \angle-26.7^{\circ} \\
289.9 \angle-146.7^{\circ} \\
289.9 \angle 93.3^{\circ}\end{array}$ & $\begin{array}{l}288.0 \angle-28.8^{\circ} \\
287.7 \angle-148.7^{\circ} \\
288.0 \angle 91.3^{\circ}\end{array}$ \\
\hline
\end{tabular}

Where $V_{1}, V_{2}$ and $V_{3}$ are phase to neutral voltages in wye connections and phase to ground voltages in the others.

For each connection, a vector named Taps is included in the tables, at second row. It represents the tap positions for the different regulators. As it can be seen, this vector includes 3 values for wye and close delta connections ( 1 regulator per phase) and 2 values for open delta configurations (2 regulators for three phases). For open delta cases there is always an empty position in Taps, that corresponds to the phase in which there is no regulator. As an example, consider case a: The 2 regulators are connected between phases $\mathrm{a} / \mathrm{b}$ and $\mathrm{c} / \mathrm{a}$ (first and third positions), so the corresponding vector Taps is of the form $[0-0]$. Between phases $b / c$ (second position) there is no regulator, so the corresponding position at vector Taps is empty. The same reasoning applies to open delta cases $\mathrm{b}$ and c. A zero in Taps means neutral position. A positive value corresponds to a raise position, varying form 1 to 16 , and a negative value is obtained for lower positions, varying from -1 to -16 .

Looking at the tables, several analysis can be done. First, comparing the voltage profiles for this specific case before and after optimization: Before optimizing, in $Y_{g} Y_{g}$ case the voltage level at node 4 is violating the voltage constraint in the 3 phases (less than $6840 \mathrm{~V}$ ), but after optimization the constraint is not violated in any phase. The minimum voltage is obtained at node 4 , phase b $6845 \mathrm{~V}(0.951 \mathrm{pu})$. A similar reasoning can be applied to connections $\Delta \Delta$ and open $\Delta$; it can be observed that in all cases the voltage constraint is fulfilled ( $11847 \mathrm{~V}$ for three wire connections).

Then, in balanced loading cases, with wye and close delta connections, the tap positions are quiet similar among different phases but not exactly the same because of the unbalanced nature of lines. In contrast, open delta connections give rise to great differences among taps because the SVR itself is not symmetric (two regulators for three phases), so even for a balanced loading scenario one regulator can be at raise position while the other can be at lower position.

Finally, for unbalanced loading cases it can be seen that the SVR, not only improves the voltage in magnitude but also leads to a more balanced scenario.

\section{Conclusion}

This work provides for the theoretical background, the model description and the diagrams needed for the inclusion of Step Voltage Regulators into a general, there phase and unbalanced power flow problem. The general model for three phase Step Voltage Regulators has been included in a 4 Node Test Feeder and solved by means of an unbalanced Backward-Forward Sweep solver. The obtained results are presented as a benchmark. The main contribution of this work is, besides the guidelines for the SVR model development, the proposal of a new 4-Node Test System for testing and evaluation of three-phase SVRs connections. The authors would like to encourage software developers to test their software using the model and data presented in this work. All results are available on-line (see Supplementary material).

\section{Appendix A. Supplementary material}

Supplementary data associated with this article can be found, in the online version, at http://dx.doi.org/10.1016/j.ijepes.2017.06. 027.

\section{References}

[1] Hobson JE, Lewis WA. Regulating transformers in power-system analysis. Electr Eng 1939;58(11):874-86.

[2] Hill LH. Step type feeder voltage regulators. Electr Eng 1935;54(2):154-8.

[3] Saidy M, Hughes F. A predictive integrated voltage regulator and power system stabilizer. Int J Electric Power Energy Syst 1995;17(2):101-11. cited By 8.

[4] Dzafic I, Jabr RA, Halilovic E, Pal BC. A sensitivity approach to model local voltage controllers in distribution networks. IEEE Trans Power Syst 2014;29 (3):1419-28.

[5] Pereira C, Castro C. Optimal placement of voltage regulators in distribution systems. In: PowerTech, 2009 IEEE Bucharest. p. 1-5. June.

[6] Watson JD, Watson NR, Das B. Effectiveness of power electronic voltage regulators in the distribution network. IET Gener Transm Distrib 2016;10 (15):3816-23.

[7] Brito MEC, Limongi LR, Cavalcanti MC, Neves FAS, Azevedo GMS. A stepdynamic voltage regulator based on cascaded reduced-power series transformers. Electric Power Syst Res 2014;108:245-53. cited By:3.

[8] Senjyu T, Miyazato Y, Yona A, Urasaki N, Funabashi T. Optimal distribution voltage control and coordination with distributed generation. IEEE Trans Power Deliv 2008;23(2):1236-42.

[9] Hossain MI, Yan R, Saha TK. Investigation of the interaction between step voltage regulators and large-scale photovoltaic systems regarding voltage regulation and unbalance. IET Renew Power Gener 2016;10(3):299-309.

[10] Liu X, Aichhorn A, Liu L, Li H. Coordinated control of distributed energy storage system with tap changer transformers for voltage rise mitigation under high photovoltaic penetration. IEEE Trans Smart Grid 2012;3(2):897-906. June.

[11] Youssef KH. A new method for online sensitivity-based distributed voltage control and short circuit analysis of unbalanced distribution feeders. IEEE Trans Smart Grid 2015;6(3):1253-60.

[12] Rahbarimagham H, Sanjari MJ, Tavakoli A, Gharehpetian GB, Jafari R. Emission reduction in a micro grid including pv considering voltage profile improvement. In: 2013 Smart Grid Conference (SGC), Dec. p. 219-24.

[13] Tang Z, Hill D, Liu T, Ma H. Hierarchical voltage control of weak subtransmission networks with high penetration of wind power. IEEE Trans Power Syst 2017;PP(99). 1-1. 
[14] Murphy KM, Nair NKC. Voltage control in distribution networks with penetration of solar pv: estimated voltages as a control input. In: 2016 IEEE Power and Energy Society General Meeting (PESGM), July. p. 1-5.

[15] Ceylan O, Dimitrovski A, Starke M, Tomsovic K. Optimal reactive power allocation for photovoltaic inverters to limit transformer tap changes. In: 2016 IEEE Power and Energy Society General Meeting (PESGM), July. p. 1-5.

[16] Farag H, El-Saadany E, El Shatshat R, Zidan A. A generalized power flow analysis for distribution systems with high penetration of distributed generation. Electric Power Syst Res 2011;81(7):1499-506. cited By 35.

[17] Oshiro M, Tanaka K, Uehara A, Senjyu T, Miyazato Y, Yona A, et al. Optimal voltage control in distribution systems with coordination of distribution installations. Int J Electric Power Energy Syst 2010;32(10):1125-34. cited By 26.

[18] Frias P, Platero CA, Soler D, Blazquez F. High-efficiency voltage regulator for rural networks. IEEE Trans Power Deliv 2010;25(3):1666-72.

[19] Chamana M, Chowdhury BH, Jahanbakhsh F. Distributed control of voltage regulating devices in the presence of high pv penetration to mitigate ramprate issues. IEEE Trans Smart Grid 2017;PP(99). 1-1.

[20] Yan R, Li Y, Saha T, Wang L, Hossain M. Modelling and analysis of open-delt step voltage regulators for unbalanced distribution network with photovoltaic power generation. IEEE Trans n Smart Grid 2017;PP(99). 1-1.

[21] Robbins BA, Zhu H, Domínguez-García AD. Optimal tap setting of voltage regulation transformers in unbalanced distribution systems. IEEE Trans Power Syst 2016;31(1):256-67.

[22] Ahmadi H, Martí JR. Distribution system optimization based on a linear powerflow formulation. IEEE Trans Power Deliv 2015;30(1):25-33.
[23] Araujo LR, Penido DRR, Carneiro S, Pereira JLR. A three-phase optimal powerflow algorithm to mitigate voltage unbalance. IEEE Trans Power Deliv 2013:28 (4):2394-402.

[24] Ghatak U, Mukherjee V. An improved load flow technique based on load current injection for modern distribution system. Int J Electric Power Energy Syst 2017;84:168-81.

[25] Liu JW, Choi SS, Chen S. Design of step dynamic voltage regulator for power quality enhancement. IEEE Trans Power Deliv 2003;18(4):1403-9.

[26] Kersting WH. The modeling and application of step voltage regulators. In: 2009 IEEE/PES power systems conference and exposition, March. p. 1-8.

[27] Kersting WH. Distribution system modeling and analysis. Abingdon: CRC Press; 2001.

[28] Distribution Test Feeders, IEEE PES Distribution System Analysis Subcommittee's. Distribution Test Feeder Working Group. Available: <http:// ewh.ieee.org/soc/pes/dsacom/testfeeders/>.

[29] Kersting WH. Transformer model test system. In: Transmission and distribution conference and exposition, 2003 IEEE PES 3. IEEE; 2003. p. 1022-6.

[30] Arboleya P, González-Morán C, Coto M. Unbalanced power flow in distribution systems with embedded transformers using the complex theory in $\alpha \beta 0$ stationary reference frame. IEEE Trans Power Syst 2014;PP(99):1-11.

[31] González-Morán C, Arboleya P, Mohamed B. Matrix backward forward sweep for unbalanced power flow in $\alpha \beta 0$ frame. Electric Power Syst Res 2017; 148:273-81. 